\title{
Solanum muricatum Aiton Juice as a Hepatoprotective Agent in Wistar Rats Induced with Carbon tetrachloride
}

\author{
Justine Sim Wei Yang, ${ }^{1}$ Istriati, ${ }^{2}$ Tiene Rostini ${ }^{3}$ \\ ${ }^{1}$ Faculty of Medicine Universitas Padjadjaran, ${ }^{2}$ Departement of Pharmacology and Therapy \\ Faculty of Medicine Universitas Padjadjaran, ${ }^{3}$ Departement of Clinical Pathology Faculty of \\ Medicine Universitas Padjadjaran/Dr. Hasan Sadikin General Hospital Bandung
}

\begin{abstract}
Background: The liver participates in various metabolic processes in human body. Exposures to toxins such as carbon tetrachloride (CCl4) result in hepatocyte destruction and release the cell contents. Pepino (Solanum muricatum Aiton) contains antioxidants that protect the liver from hepatoxicity. The aim of this experiment was to determine the effect of pepino in protecting the hepatocyte from hepatotoxic effect of $\mathrm{CCl} 4$.

Methods: A total of 16 Wistar rats were divided into control and therapeutic groups. The control group was given pepino juice for 10 days. For induction of hepatotoxicity, CCl4 10\% was given at a dosage of 2.0 $\mathrm{mL} / \mathrm{kg}$ intra-peritoneal. The therapeutic group was given $1.0 \mathrm{~mL}$ of $300 \mathrm{~g} / \mathrm{mL}$ pepino juice via oral feeding. Hepatoxicity was measured through SGPT level in both groups T-test was used to analyze the data.

Results: The therapeutic group showed a larger decrease (6898.9 IU/L-79.1 IU/L) in SGPT level compared to the control group $(6469.8 \mathrm{IU} / \mathrm{L}-418.5 \mathrm{IU} / \mathrm{L})$ P-value $<0.05$. The SGPT level in the therapeutic group reached normal baseline $(50 \mathrm{IU} / \mathrm{L}-150 \mathrm{IU} / \mathrm{L}$.

Conclusions: Pepinojuice at the dosage of $300 \mathrm{~g} / \mathrm{mL}$ may have hepatoprotective effect. [AM].2015;2(4):541-5]

Keywords: Carbon tetrachloride, hepatotoxicity, Pepino, Solanum muricatum Aiton, SGPT
\end{abstract}

\section{Introduction}

Hepatotoxics are chemicals that are harmful to the liver. Prolonged exposure towards these substances may lead to hepatotoxicity. Carbon tetrachloride $\left(\mathrm{CCl}_{4}\right)$ is a potent hepatotoxin. It is widely use in experiments as an inducer of hepatotoxicity to animal models. ${ }^{1,2}$

The $\mathrm{CCl}_{4}$ is metabolized by the liver enzyme family Cytochrome P450 of the mixed function oxidase system. This process produces free radical of trichloromethylperoxyl $\left(\mathrm{OOCCl}_{3}\right)$ that could damage the hepatocyte.,3

Patients with $\mathrm{CCl}_{4}$ hepatotoxicity, most commonly experience symptoms such as jaundice, fatigue, lethargic, manifestation of hypersensitivity, nausea, vomiting, diarrhea, dyspnea and syncope. They might also experience pain and tenderness in right upper quadrant and abdominal distension due to hepatomegaly. Other common findings in physical examinations are peripheral edema and ascites. 3,4
In routine laboratory examinations, common findings in hepatotoxic patients are elevated liver enzymes, especially serum glutamic pyruvic transaminase (SGPT), serum glutamic oxaloacetate transaminase (SGOT), and lactate dehydrogenase (LDH), leukocytosis, hypoalbuminemia, increased low density lipoprotein (LDL) and increased total cholesterol. . $^{3-5}$

The SGPT and SGOT are essential for synthesis and degradation of amino acids. SGPT are usually found in the liver and a lesser extent in the kidney while SGOT had a wider distribution in human body (liver, heart, brain, skeletal muscle, kidney, and erythrocyte). The SGPT has half-life of 47 hours compared to SGOT which is 17 hours. This made SGPT a better indicator of hepatocyte damage. ${ }^{5,6}$

Further, Pepino (Solanum murcatum Aiton) is a fruit, categorized under the family of Solanaceae, a shrub type of plant. Pepino originated from the Andeans, particularly Peru. It is cultivated through its stem and

Correspondence: Justine Sim Wei Yang, Faculty of Medicine, Universitas Padjadjaran, Jalan Raya Bandung-Sumedang Km.21, Jatinangor, Sumedang, Indonesia, Phone: +62818626924 Email: masterpiece_jswy@hotmail.com 
will yield an edible fruit which smells great, juicy, mild sweetness and varies in intensity of color and shape (usually oval). Currently, it is also being planted in some parts of China. In Indonesia, pepino was introduced in the $19^{\text {th }}$ century during the Dutch's colonization in the country. The known usage of pepino is for its antioxidants, anti-diabetic and anti-gastric ulcer. $^{7-10}$

This study was conducted to study the effect of pepino juice on the SGPT level of hepatotoxic male Wistar rats induced with $\mathrm{CCl}_{4}$.

\section{Methods}

This experimental procedure was conducted in the Pharmacology Laboratory of Faculty of Medicine, Universitas Padjadjaran from November-December 2012. A total of 16 Wistar rats about 7 weeks old, weighing approximately 130 gram-250 gram, was obtained from Bandung Institute of Technology. The Wistar rats were adapted for 7 days. Throughout this study, the Wistar rats were provided with adequate rat pellets and water. $^{11,12}$

The Wistar rats were divided into two groups and were housed in cages according to the assigned group. Group 1 being the Control group, the Wistar rats were induced with $\mathrm{CCl}_{4}$ and they were not given pepino juice. On the other hand, Group 2 was the Therapeutic group. The Wistar rats in the Therapeutic group were induced with $\mathrm{CCl}_{4}$ and were given pepino juice.

The pepino was obtained from Carrefour, Paris van Java, in Bandung. For 10 days, about 300 gram of pepino fruit were skinned, sliced and blended daily in a food processor to obtain the juice. About $280 \mathrm{ml}$ of juice was obtained from the process. Then, $1.0 \mathrm{ml}$ of pepino juice was being fed to the Wistar rats in the Therapeutic group via oral feeding tube. ${ }^{9,10}$

After one week of adaptation, the Wistar rats in both Control and Therapeutic group were injected with $2.0 \mathrm{ml} / \mathrm{kg}$ body weight of $\mathrm{CCl}_{4}$ intra peritoneal in a single dose. The Wistar rats were allowed to rest for 24 hours before withdrawal of blood for SGPT assay. Approximately 20 minutes prior to blood collection, the Wistar rats were heated in the warming box at temperature of $39^{\circ} \mathrm{C}$ to ensure vasodilatation. Simultaneously, the Wistar rats were observed for heat induced distress and also dehydration indicated by excess salivation. ${ }^{13}$

The Wistar rats were taken out of the warming box, one at a time. The tail of the
Wistar rat was cleaned with cotton soaked in ethanol solution. This is the aseptic and antiseptic technique to prevent the Wistar rat from infection. Afterward, finger pressure was applied at $5 \mathrm{~cm}$ from the tip of the Wistar rat's tail to enhance the visibility of the blood vessel and venous blood was obtained by cutting the edge of the tail of the Wistar rat with a sterile scalpel. $^{1,13}$

Then, about $1.0 \mathrm{ml}$ of venous blood was collected in a test tube, centrifuged at $3,000 \mathrm{rpm}$ for 15 minutes to separate the blood cells and serum. Next, $0.05 \mathrm{ml}$ of serum was transferred into a cuvette, and then $0.25 \mathrm{ml}$ of substrate containing alanine and alpha ketoglutarate was added. The sample was incubated at $37^{\circ} \mathrm{C}$ for 30 minutes. After 30 minutes, 0.25 $\mathrm{ml}$ of 2, 4-dinitrophenylhydrazine (DPNH) was added to the mixture. The sample was incubated at a temperature of $37^{\circ} \mathrm{C}$ for another 20 minutes before inserted into the spectrophotometer.,12,14

Subsequently, the spectrophotometer was switched on, and the wavelength was adjusted to $340 \mathrm{~nm}$. The cuvette containing yellow complex of Wistar rat serum and substrate was inserted into the spectrophotometer to measure the SGPT level. ${ }^{12,14}$ This procedure was repeated on day 11 after the Wistar rats in the Therapeutic group completed their therapy [ $1.0 \mathrm{ml}$ of pepino juice fed for 10 days].

Furthermore, data about SGPT level of Wistar rats in both groups were collected. The Shaphiro Wilk test was conducted first to ensure normal distribution of the data and Statistical T test was used to compare the SGPT level for both groups.

\section{Results}

The Shaphiro-Wilk test showed a normal distribution of the data. The data collected was summarized in Figure 1. The Wistar rats in both groups showed an increase in SGPT level 24 hours after $\mathrm{CCl}_{4}$ injection. The Wistar rats in both groups also showed a decrease in SGPT level 11 days later. However, the SGPT level in the Control group was still considered high because the normal SGPT range in Wistar rats were $50 \mathrm{IU} / \mathrm{L}-150 \mathrm{IU} / \mathrm{L}$.

The Unpaired T-test was performed to test whether there was a significant difference between SGPT levels of the Wistar rats in both groups. The result of the Unpaired T-test is shown in Table 1.

The result of Unpaired T-test shows that the mean SGPT level of the Wistar rats in the Therapeutic group reached the normal 


\section{Difference in SGPT level of Wistar rats in both groups, pre-therapy and post- therapy}

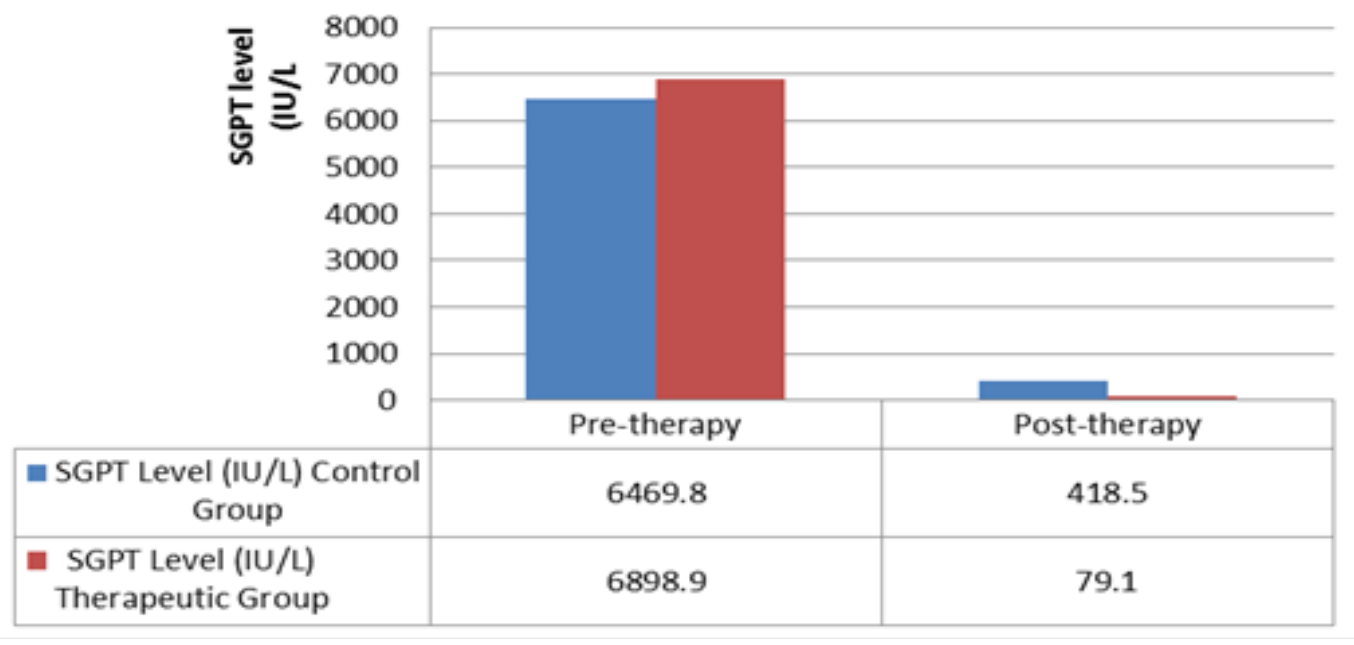

Figure 1 Difference in SGPT level of Wistar rats in both groups, pre-therapy and post-therapy

Note: $\bullet$ Pre-therapy $=$ SGPT level 24 hours after induction of hepatotoxicity -Post-therapy = SGPT level 24 hours after Wistar rats in Therapeutic group completed the 10 days course of therapy with pepino juice

baseline, which was between $50 \mathrm{IU} / \mathrm{L}-150$ IU/L. Meanwhile, the mean SGPT level of the Wistar rats in the Control group never reached the normal baseline.

In addition, the result also showed that there was a significant decrease in SGPT level of Wistar rats in Therapeutic group. This deduction was indicated by the $\mathrm{p}$ value calculated to be 0.000 , which was smaller in comparison to $\alpha=5 \%(0.05)$.

\section{Discussion}

According to a previous study, $2.5 \mathrm{ml} /$ $\mathrm{kg}$ concentration of body weight of $\mathrm{CCl}_{4}$ is enough to induce hepatotoxicity in Wistar rats. However, considering the cost of the experiment, the dosage of $\mathrm{CCl}_{4}$ is adjusted to
$2.0 \mathrm{ml} / \mathrm{kg}$ of body weight of the Wistar rats. The Wistar rats are considered hepatotoxic when their SGPT level increases beyond 160 $\mathrm{IU} / \mathrm{L}$ for a male Wistar rat. ${ }^{1,2,15}$

Based on the data collected, the Wistar rat in the Control group showed a decreased in SGPT levels (6469.80 IU/L-418.50 IU/L). The increase in SGPT levels indicated that the hepatocyte was being damaged by $\mathrm{CCl}_{4}$. The mechanism of $\mathrm{CCl}_{4}$ to induce injury was caused by Cytochrome P450 enzyme in the liver. This enzyme metabolized the $\mathrm{CCl}_{4}$, by firstly inducing homolytic fission. This homolytic fission yields trichloromethyl radical $\left(\mathrm{CCl}_{3}\right)^{2,12,15}$

The next step was an oxidation process which involved the combination of this $\mathrm{CCl} 3$ with oxygen $\left(\mathrm{O}_{2}\right)$ and $00 \mathrm{CCl}_{3}$ were produced. These free radicals of $\mathrm{OOCCl}_{3}$ were responsible

Table 1 Unpaired T-test

\begin{tabular}{llcccccc}
\hline \multicolumn{2}{c}{ SGPT level } & n & SGPT (IU/L) & \pm & SD & Calculatedt & P Value \\
\hline \multirow{2}{*}{ Post therapeutic } & Control & 8 & 418.5 & \pm & 66.2 & & \\
& Therapeutic & 8 & 79.1 & \pm & 15.5 & & 0.000 \\
\hline
\end{tabular}

SD: Standard Deviation 
for the damage to the semi permeable lipid membrane of the hepatocytes, altering the permeability of membrane. Moreover, the increased permeability of membrane leads to swelling of hepatocytes, inactivation of mitochondria enzymes and necrosis of the hepatocyte that cause an increased SGPT level. ${ }^{2,12}$

The normal mechanism of a human body to metabolize the product $\mathrm{CCl} 4$ is to oxidize the $\mathrm{CCl}_{3}$ under aerobic condition. This process yields trichloromethanol $\left(\mathrm{Cl}_{3} \mathrm{COH}\right)$ which is the precursor for phosgene $\left(\mathrm{COCl}_{3}\right) \cdot \mathrm{Cl}_{3} \mathrm{COH}$ is then oxidized into $\mathrm{COCl}_{3}$. Microsomal enzyme produced by the hepatocyte will react with $\mathrm{COCl}_{3}$ via hydrolytic chlorination to produce carbon dioxide $\left(\mathrm{CO}_{2}\right)^{1,2,12,14}$

Although the SGPT level of Wistar rats in the Control group decreased, it was still within abnormal range (beyond $160 \mathrm{IU} / \mathrm{L}$ ), which means the Wistar rats were still considered hepatotoxic. The decrease in SGPT level indicates that the hepatocyte of Wistar rats regenerates rapidly in a period of 10 days to overcome the damage caused by $\mathrm{CCl}_{4}{ }^{1,12,14}$

The liver regained the function to metabolize protein through regeneration of hepatocytes. The SGPT level decreased in the Wistar rats of the Control group because it was being degraded. However, since the damaged caused to hepatocyte of the Wistar rats in the Control group was not fully reversible yet, thus the SGPT level never reached normal. . $^{1,2,14}$

On the other hand, the decrease in SGPT level of Wistar rats from the Therapeutic group (from an average of 6898.90 IU/L-79.10 IU/L) shows that the SGPT level of Wistar rats that were being fed with pepino juice for 10 days, decreased to a normal baseline (50 IU/L-150 $\mathrm{IU} / \mathrm{L}$ ).

The decrease in SGPT level of Wistar rats in the Therapeutic group is due to the antioxidants in pepino that protects the hepatocytes of the Wistar rat from being damaged by $\mathrm{CCl}_{4}$. A previous research proposed that pepino contains antioxidant properties. Pepino can reduce the reactive oxygen species level, increase glutathione level, retaining glutathione peroxidase and catalase activities in cardiac tissues. This shows that, antioxidant of pepino is able to protect organs from free radical damage. ${ }^{7-10}$

The synergistic effect from the antioxidants of pepino juice that protects the liver and also hepatocyte regeneration rapidly decreased the SGPT level of Wistar rats in the Therapeutic group to a normal baseline.

Therefore, this study concludes that pepino juice has a hepatoprotective effect on hepatotoxic Wistar rats.

\section{References}

1. Akram E, Olamafar S, Zaringhalam J, Rezazadeh S, Eidi M. Protective effect of Walnut (Juglans regia L.) extract against CCl4-induced hepatotoxicity in rats. Pejouhesh. 2011;35(2):87-92.

2. Weber LW, Boll M, Stampfl A. Hepatotoxicity and mechanism of action of haloalkanes: carbon tetrachloride as a toxicological model. Crit Rev Toxicol. 2003;33(2):10536.

3. Navarro VJ, Senior JR. Drug-Related Hepatotoxicity. N Engl J Med. 2006;354(7):731-9.

4. Dooley JS, Lok A, Burroughs A, Heathcote J, editors. Sherlock's Diseases of the Liver and Biliary System. 12th ed. Oxford:WileyBlackwell; 2011.

5. McPherson RA, Pincus MR, Henry JB. Henry's Clinical Diagnosis and Management by Laboratory Methods. 21st ed. Philadelphia: Saunders Elsevier; 2007.

6. Giboney PT. Mildly elevated liver transaminase levels in the asymptomatic patient. Am Fam Physician. 2005;71(6): 1105-10.

7. Hsu C, Guo Y, Wang Z, Yin M. Protective effects of an aqueous extract from pepino (Solanum muricatum Ait.) in diabetic mice. J Sci Food Agric. 2011;91(8):1517-22.

8. Arindah D. Fractionation and Identification of Compound In Fruit Meat of Solanum muricatum Aiton that has Potential as Antioxidants [dissertation]. Malang: Universitas Islam Negeri Maulana Malik Ibrahim; In Press 2010.

9. Sudha G, Priya MS, Shree RB, Vadivukkarasi S. Antioxidant activity of ripe and unripe pepino fruit (Solanum muricatum Aiton). J Food Sci. 2012;77(11):1131-5.

10. Saptarini N.M., Suryasaputra D., A.M. S. Analisis Rasio Proteksi Antiulser Sari Buah Pepino (Solanum muricatum Aiton) Menggunakan Mencit sebagai Model Hewan Coba. Majalah Obat Tradisional. 2011;16(2):75-80.

11. Galal RM,Zaki HF, Seif El-Nasr MM, Agha AM. Potential protective effect of honey against paracetamol-induced hepatotoxicity. Arch Iran Med. 2012;15(11):674-80.

12. Feng Y, Siu K, Ye X, Wang N, Yuen M, Leung C, et al. Hepatoprotective effects of berberine on carbon tetrachloride-induced acute hepatotoxicity in rats. Chinese medicine. 
2010;5(1):1-6.

13. Parasuraman S, Raveendran R, Kesavan R. Blood sample collection in small laboratory animals. J Pharmacol Pharmacother. 2010; 1(2):87-93.

14. Domitrović R, Jakovac H, Blagojević G. Hepatoprotective activity of berberine is mediated by inhibition of TNF- $\alpha$, COX-2, and iNOS expression in CCl4 intoxicated mice. Toxicology. 2011;280(1-2):33-43.

15. Wong LL, Fan ST, Man K, Sit WH, Jiang PP, Jor IW, et al. Identification of liver proteins and their roles associated with carbon tetrachloride-induced hepatotoxicity. Hum Exp Toxicol. 2011;30(9):1369-81. 